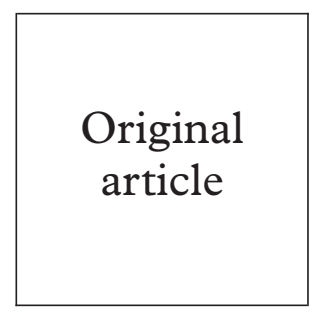

\title{
Inequalities in rates of gonorrhoea and chlamydia between black ethnic groups in south east London: cross sectional study
}

\author{
Nicola Low, Jonathan A C Sterne, David Barlow
}

Objectives: To examine differences in population based rates of gonorrhoea and chlamydia between black ethnic groups in Lambeth, Southwark and Lewisham Health Authority. Methods: Episodes of gonorrhoea or chlamydia recorded among attenders at 11 genitourinary clinics in south and central London from 1 January 1994 to 31 December 1995 were retrieved. Complete data on chlamydia were only available for women. Ethnic group was assigned according to census categories - white, black Caribbean, black African, black other, Asian, or other. We calculated yearly incidence rates for episodes of gonorrhoea and chlamydia in residents of Lambeth, Southwark and Lewisham Health Authority. Random effects Poisson regression models were used to examine associations between infection rates and age, ethnic group, and material deprivation.

Results: During the study period there were 1996 episodes of gonorrhoea in men and women and 1376 episodes of chlamydia in women with complete data. For both infections rates among individuals from black Caribbean and black other ethnic groups were markedly higher than among black Africans. In men, the gonorrhoea rate among black Caribbean 20-24 year olds was 2348 (95\% CI 1965 to 2831) episodes per 100000 compared with 931 (95\% CI 690 to 1288) in black African men and 111 (95\% CI 100 to 124) per 100000 in white men of the same age. Among women gonorrhoea rates were highest in black Caribbean 15-19 year olds (2612, 95\% CI 2161 to 3190 per 100000$)$. In contrast, rates in black African women of the same age (331, 95\% CI 154 to 846 per 100000 ) were similar to those of white women (222, 95\% CI 163 to 312 ). Chlamydia rates were also highest in black Caribbean 15-19 year old women (4579, 95\% CI 3966 to 5314 per 100 000), compared with 1286 (95\% CI 907 to 1888) in black African and 433 (95\% CI 349 to 544) per 100000 white women. Controlling for material deprivation and age only attenuated differences in rates between ethnic groups slightly.

Conclusions: There are marked differences in rates of gonorrhoea and chlamydia between different black ethnic groups, with higher rates in black Caribbeans than black Africans. This study supports the hypothesis that assortative sexual mixing patterns can restrict epidemics of sexually transmitted infections within ethnic groups. Differences in disease occurrence between black ethnic groups should be explored before combining data, even when numbers of episodes are small. (Sex Transm Inf 2001;77:15-20)

Keywords: gonorrhoea; chlamydia infections; ethnic groups

\section{Introduction}

Inequalities in rates of sexually transmitted infections between ethnic or racial groups have long been recorded across the United States ${ }^{1}$ and have now been described in both urban settings and in shire counties in England. ${ }^{2-6}$ In these studies people from different black ethnic groups, such as black Caribbean and black African have been considered as a single category because of variations in data collected from difference sources, ${ }^{5}$ because numbers in a specific group were considered too low to estimate rates reliably, ${ }^{24}$ or for no stated reason. ${ }^{36}$ In the United States, national infectious diseases surveillance systems ${ }^{1}$ and ad hoc studies $^{7-9}$ also consider African-Americans together with individuals from other black ethnic groups. Averaging across groups is convenient for statistical analyses but may be misleading and mask differences that are important for aetiological studies and for targeting interventions. ${ }^{5}$ In addition, the term "black" is often used to describe a racial group so, when applied to people of both Caribbean and African descent, it emphasises an association with the biological attribute of skin colour. ${ }^{10}$ Explanations in terms of common cultural, social and behavioural factors might consequently be less likely to be proffered. ${ }^{11}$

Since April 1995 ethnic group data for monitoring access to health services have been collected by NHS outpatient departments using the categories of the 1991 census and are therefore readily available for the description of ethnic differences in health service use. ${ }^{11}$ We used these data, collected from departments of genitourinary medicine, to investigate differences in rates of gonorrhoea and chlamydia between different black ethnic groups among residents of Lambeth, Southwark and Lewisham Health Authority; $25 \%$ of the population are from non-white ethnic groups (table 1), ${ }^{12}$ and most of these are black people of Caribbean and west African extraction.

\section{Methods}

Methods of data collection have been described in detail previously. ${ }^{5}$ Briefly, episodes of gonorrhoea or chlamydia recorded among attenders at 11 genitourinary clinics in south 
Table 1 Categories of ethnic group used in the census and in analyses

\begin{tabular}{|c|c|c|c|}
\hline Census category & $\begin{array}{l}\% \text { of population } \\
\text { in census group }\end{array}$ & Data recorded by clinics & Study category \\
\hline White & 74.3 & $\begin{array}{l}\text { White ethnicity } \\
\text { White race } \\
\text { European, North American, Australian, or } \\
\text { New Zealand nationality, or country of birth }\end{array}$ & White \\
\hline Black Caribbean & 10.4 & $\begin{array}{l}\text { Black Caribbean ethnicity } \\
\text { West Indian nationality or country of birth }\end{array}$ & Black Caribbean \\
\hline Black African & 5.8 & $\begin{array}{l}\text { Black African ethnicity } \\
\text { African nationality or country of birth }\end{array}$ & Black African \\
\hline Black other & 2.5 & $\begin{array}{l}\text { Black other ethnicity } \\
\text { Afro-Caribbean ethnicity } \\
\text { Black race }\end{array}$ & Black other \\
\hline $\begin{array}{l}\text { Indian } \\
\text { Pakistani }\end{array}$ & $\begin{array}{l}1.5 \\
0.5\end{array}$ & $\begin{array}{l}\text { Indian, Pakistani, or Bangladeshi ethnicity, } \\
\text { nationality of country of birth }\end{array}$ & \\
\hline Bangladeshi & 0.6 & & \\
\hline Chinese & 1.2 & $\begin{array}{l}\text { Chinese ethnicity, nationality, or country of } \\
\text { birth }\end{array}$ & Asian/other \\
\hline Other Asian & 1.2 & $\begin{array}{l}\text { All other Asian ethnicity, nationality, or } \\
\text { country of birth }\end{array}$ & \\
\hline Other & 1.9 & $\begin{array}{l}\text { All other ethnic groups, nationalities, or } \\
\text { countries of birth }\end{array}$ & \\
\hline
\end{tabular}

${ }^{\star}$ Population at 1991 census. From Annual Report of the Director of Public Health. ${ }^{12}$

and central London from 1 January 1994 to 31 December 1995 were retrieved. Episodes of infection were identified by KC60 codes used for surveillance reports and residence in the study area was determined from the postcode. Multiple episodes in the same person were defined as a KC60 code for the same infection recorded 4 or more weeks after a previous diagnosis in records with the same sex, date of birth, and postcode. Data on chlamydia were only collected for women because testing in men was not routinely performed at all clinics during the study period and co-infection with gonorrhoea and chlamydia could not be reliably determined because data were compiled separately for each infection.

\section{CATEGORISATION OF ETHNIC GROUP}

Categorisation of ethnic groups in the original report $^{5}$ used three broad groupings-white, black, and other-because five of 11 centres did not collect data in categories consistent with the census for some or all of the study period. These centres recorded racial group, country of birth, or nationality. In this study we used the census categories-white, black Caribbean, black African, black other, Asian, or other and, if these were unavailable, we assigned individuals' race, country of birth or nationality to an ethnic group according to predefined rules (table 1). The group "black other" consists mostly of people from Caribbean backgrounds born in the United Kingdom. ${ }^{13}{ }^{14}$ Records with nationality or country of birth recorded only as "United Kingdom" or with missing information were coded as unknown and were excluded from analysis because there was no available population denominator for this group. Episodes of infection in individuals aged below 15 or over 59 years at the time of diagnosis and records with no postcode or a postcode outside Lambeth, Southwark and Lewisham Health Authority boundaries were also excluded.
STATISTICAL ANALYSIS

The dataset was rendered anonymous by deleting dates of birth and postcodes and by categorising age. Analyses were based on the number of eligible episodes of infection rather than the number of individuals. We calculated yearly incidence rates of gonorrhoea and chlamydia using methods for calculating confidence intervals that took into account the occurrence of multiple episodes within individuals. The uninfected denominator population was estimated from the 1991 census, after subtracting the number of infected people in strata defined by sex, age, ethnic group, and ward of residence. Person time at risk for each episode was calculated as the time to infection from 1 January 1994 or from the date of the last episode. All individuals were considered to remain at risk throughout the 2 year study period, with no immunity following an episode of infection. Census population counts were adjusted for undercoverage in inner London using published adjustment factors specific for sex and age. ${ }^{15}$

We used random effects Poisson regression models to examine associations between gonococcal or chlamydial infection and the effects of age, ethnic group, and material deprivation, taking multiple episodes of infection into account. Material deprivation at ward level was measured using the Townsend score, which combines census derived measures of unemployment, overcrowding, and car and home ownership, with higher scores indicating increasing deprivation. Results are expressed as infection rate ratios, with $95 \%$ confidence intervals, compared with the baseline category. Separate regression models are presented for men and women because of strong evidence $(p<0.0001)$ for interaction between the effects of both sex and age and sex and ethnic group.

\section{Results}

From 1 January 1994 to 31 December 1995, 2256 episodes of gonorrhoea in men and 
Table 2 Distribution of episodes of gonorrhoea and chlamydia diagnosed from 1 Fanuary 1994 to 31 December 1995 among residents of Lambeth, Southwark and Lewisham presenting to genitourinary clinics in London

\begin{tabular}{|c|c|c|c|}
\hline \multirow[b]{2}{*}{ Variable } & \multicolumn{2}{|l|}{ Gonorrhoea } & \multirow{2}{*}{$\begin{array}{l}\text { Chlamydia } \\
\text { Women } \\
(n=1376) \\
\text { No }(\%)\end{array}$} \\
\hline & $\begin{array}{l}\text { Men }(n=1314) \\
\text { No }(\%)\end{array}$ & $\begin{array}{l}\text { Women } \\
(n=682) \\
\text { No }(\%)\end{array}$ & \\
\hline \multicolumn{4}{|l|}{$\operatorname{Age}^{\star}$} \\
\hline $15-19$ years & $136(10.4)$ & $222(32.6)$ & $413(30.0)$ \\
\hline $20-24$ years & $337(25.7)$ & $239(35.0)$ & $454(33.0)$ \\
\hline $25-29$ years & $406(30.9)$ & $130(19.1)$ & $279(20.3)$ \\
\hline $30-59$ years & $435(33.1)$ & $91(13.3)$ & $230(16.7)$ \\
\hline \multicolumn{4}{|l|}{ Number of episodes in study period $\dagger$} \\
\hline One & $1036(89.3)$ & $544(89.5)$ & $1155(92.0)$ \\
\hline Two & $87(6.9)$ & $55(9.1)$ & $87(6.9)$ \\
\hline Three or more & $20(3.8)$ & $9(1.4)$ & $14(1.1)$ \\
\hline \multicolumn{4}{|l|}{ Clinic attended ${ }^{\star}$} \\
\hline In Lambeth, Southwark and Lewisham & $1089(82.9)$ & $645(94.6)$ & $1248(90.7)$ \\
\hline Other south London & $45(3.4)$ & $24(3.5)$ & $53(3.9)$ \\
\hline Central London & $180(13.7)$ & $13(1.9)$ & $75(5.5)$ \\
\hline Townsend score, mean (SD) $\ddagger$ & $8.2(2.4)$ & $8.1(2.5)$ & $7.9(2.5)$ \\
\hline
\end{tabular}

${ }^{\star} \mathrm{p}<0.0001$ by $\chi^{2}$ test.

†Totals are number of individuals rather than number of episodes. $\mathrm{p}=0.36$ by $\chi^{2}$ test. $\ddagger \mathrm{p}=0.002$ by one way analysis of variance.

women and 1556 episodes of chlamydia in women with a postcode in Lambeth, Southwark and Lewisham HA were recorded from 11 departments of genitourinary medicine. Data from 260 gonorrhoea and 180 chlamydia episodes with unknown age or ethnic group or that were multiple records of the same episode were excluded. Therefore, 1996 episodes of gonorrhoea in 1768 individuals (1160 men, 608 women) and 1376 episodes of chlamydia in 1257 women were available for analysis. Seventy seven of 1996 (3.9\%) gonorrhoea and $45 / 1376(3.3 \%)$ chlamydia episodes with black race recorded were coded as black other. Six episodes in people with African nationality or countries of origin were coded as black African, eight born in the West Indies were coded as black Caribbean, and five born in Asian countries were coded as Asian/other. Information about homosexual or heterosexual acquisition of infection was absent for 621/ $1160(53.5 \%)$ of males and was not considered further.

Table 2 shows the distribution of episodes of gonorrhoea and chlamydia recorded during the study period according to demographic and social characteristics. About $10 \%$ of individuals with either gonorrhoea or chlamydia experienced more than one episode of infection, accounting for around $20 \%$ of all episodes. The occurrence of multiple episodes of infection differed between ethnic groups for gonorrhoea $(\mathrm{p}=0.008)$ but not for chlamydia $(\mathrm{p}=0.14$, data not shown). In particular, $6 \%$ of black African patients had more than one episode of gonorrhoea during the study period compared with $9 \%$ of white and Asian/other and $12-15 \%$ of black Caribbean and black other individuals, respectively.

\section{RATES OF INFECTION IN DIFFERENT ETHNIC} GROUPS

Table 3 shows episode based rates according to ethnic group. For both infections the highest rates were seen among black Caribbean and black other ethnic groups. Rates of both gonorrhoea and chlamydia among black Africans were markedly lower than among the other black ethnic groups. Rates of gonorrhoea in men from white and Asian/other ethnic groups were similar while white women had the lowest rates of both infections.

Figure 1 shows rates of infection by age and ethnic group. For clarity, the graphs show data only for black Caribbean, black African, and white ethnic groups. Rates are presented on a logarithmic scale because this demonstrates relative differences between groups more readily than plots of absolute rates. The highest rates of gonorrhoea in men were seen among black Caribbean 20-24 year olds (2348, 95\% CI 1965 to 2831 per 100 000) with rates higher than 1700 per 100000 in $15-19$ and 25-29 year olds. The highest rate in black African men was 931 (95\% CI 690 to 1288) per 100000 in $20-24$ year olds and that in white men 172 (95\% CI 144 to 208) per 100000 in 25-29 year olds. Male gonorrhoea rates varied little by age and ethnic differences were maintained, with rates in black Caribbeans two to three times higher than in black Africans at all ages.

Among women, rates of infection were higher for chlamydia than for gonorrhoea. Age specific patterns were, however, similar with a decline from the youngest to oldest in all ethnic groups except for black African women with gonorrhoea. Black Caribbean women aged 15-19 years had the highest rates of gonorrhoea $(2612,95 \%$ CI 2161 to 3190 per 100 000). Rates in black African women of the same age $(331,95 \%$ CI 154 to 846 per $100000)$ were similar to those of white women (222, 95\% CI 163 to 312 ). Gonorrhoea rates were at least three and a half times higher in black Caribbean than African women at all ages. Chlamydia rates were also highest in black Caribbean 15-19 year old women (4579, 95\% CI 3966 to 5314 per 100 000), compared with 1286 (95\% CI 907 to 1888 ) per 100000 in black African and 433 (95\% CI 349 to 544) per 100000 white women.

Table 3 Episode based rates (per 100000 population aged 15-59 years) of gonorrhoea and chlamydia in residents of Lambeth, Southwark and Lewisham, by ethnic group

\begin{tabular}{|c|c|c|c|c|c|c|}
\hline & \multicolumn{4}{|c|}{ Gonorrhoea } & \multicolumn{2}{|c|}{$\begin{array}{l}\text { Chlamydia } \\
\text { Women }\end{array}$} \\
\hline & $\begin{array}{l}\text { Men } \\
\text { No }\end{array}$ & Rate $(95 \%$ CI) & $\begin{array}{l}\text { Women } \\
\text { No }\end{array}$ & Rate $(95 \%$ CI) & $\begin{array}{l}\text { Women } \\
\text { No }\end{array}$ & Rate (95\% CI) \\
\hline White & 379 & $110.8(99.5$ to 123.7$)$ & 152 & $45.2(38.0$ to 54.3$)$ & 424 & 126.2 (113.8 to 140.3$)$ \\
\hline Black Caribbean & 607 & $1381.9(1262.4$ to 1516.2$)$ & 359 & 640.7 (570.9 to 721.6$)$ & 608 & 1085.3 (995.6 to 1185.5$)$ \\
\hline Black African & 150 & $527.1(448.0$ to 624.6$)$ & 45 & $148.4(109.1$ to 207.4$)$ & 128 & $422.3(352.4$ to 510.5$)$ \\
\hline Black other & 141 & 1688.1 (1379.0 to 2089.7$)$ & 88 & $886.0(712.2$ to 1116.7$)$ & 103 & 1038.5 (839.0 to 1301.6$)$ \\
\hline Asian/other & 37 & $112.9(79.9$ to 164.9$)$ & 38 & $118.4(84.3$ to 171.7$)$ & 113 & $352.0(291.7$ to 428.9$)$ \\
\hline All ethnic groups & 1314 & $288.4(271.4$ to 306.8$)$ & 682 & $146.9(135.2$ to 159.9$)$ & 1376 & $296.3(279.8$ to 314.1$)$ \\
\hline
\end{tabular}



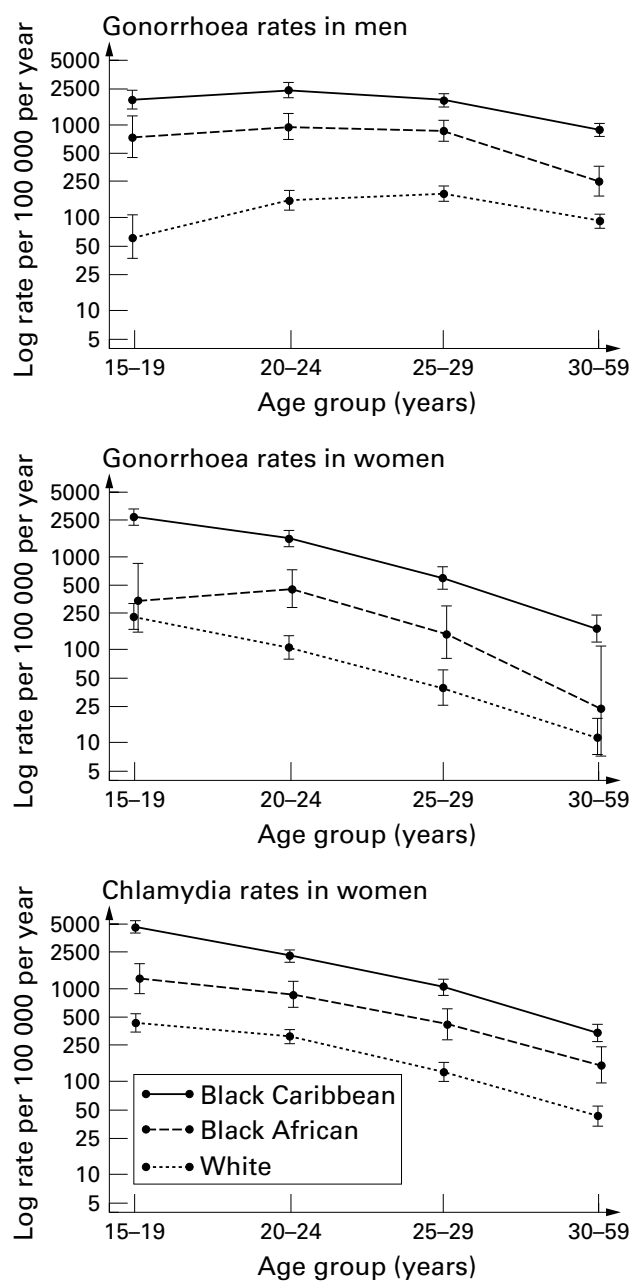

Figure 1 Episode based rates of gonorrhoea and chlamydia in residents of Lambeth, Southwark and Lewisham from black Caribbean, black African, and white ethnic groups, by age (rates plotted on a logarithmic scale).

ASSOCIATIONS BETWEEN ETHNIC GROUP AND RATES OF GONORRHOEA AND CHLAMYDIA Gonorrhoea and chlamydia rates were strongly associated with ethnic group, age, and material deprivation as measured by the Townsend score in the ward of residence. The three exposures are also related to one another. Control- ling for age reduced the strength of association between ethnic group and infection and controlling for ethnic group attenuated the association between deprivation and infection (data not shown). Table 4 shows the independent effects of each factor after controlling for confounding by the other two variables.

\section{GONORRHOEA}

Compared with the white ethnic group, gonorrhoea rates in black Caribbean and black other men and women were 12-13 times higher while those in black Africans were three to four times higher. Rates of gonorrhoea in Asian/ other men did not differ from those in white men after controlling for age and deprivation while rates in Asian/other women remained twice as high as those in white women.

\section{CHLAMYDIA}

The association between ethnic group and chlamydia was less strong than that with gonorrhoea. After controlling for confounding, rates in black Caribbean women were eight times higher and those in black African and Asian/other women two to three times higher than in white women. Chlamydia infection was also less strongly associated with material deprivation than was gonorrhoea.

\section{Discussion}

This study has shown that rates of gonorrhoea and chlamydia in residents of Lambeth, Southwark and Lewisham HA differ between black ethnic groups as well as across ethnic groups, with higher rates among individuals from black Caribbean and black other than in black Africans. These differences were not explained by age or levels of deprivation in the area of residence. Individuals from white and Asian/ other ethnic groups had the lowest recorded rates of both infections.

\section{METHODOLOGICAL ISSUES}

This study design permitted population based rates of gonorrhoea and chlamydia to be calculated. We calculated episode based rates, which include repeated infections in high level trans-

Table 4 Multivariable analysis of associations between rates of infection and ethnic group, age, and Townsend score*

\begin{tabular}{|c|c|c|c|c|c|c|}
\hline & \multicolumn{4}{|l|}{ Gonorrhoea } & \multicolumn{2}{|l|}{ Chlamydia } \\
\hline & $\begin{array}{l}\text { Men } \\
\text { Rate ratio }(95 \% \text { CI) }\end{array}$ & $p$ Valuet & $\begin{array}{l}\text { Women } \\
\text { Rate ratio }(95 \% \text { CI) }\end{array}$ & $p$ Valuet & $\begin{array}{l}\text { Women } \\
\text { Rate ratio }(95 \% \text { CI) }\end{array}$ & $p$ Valuet \\
\hline Ethnic group & & $<0.0001$ & & $<0.0001$ & & $<0.0001$ \\
\hline White & 1 (reference) & & 1 (reference) & & 1 (reference) & \\
\hline Black Caribbean & $11.6(10.1$ to 13.4$)$ & & $13.2(10.7$ to 16.2$)$ & & $8.1(7.1$ to 9.3$)$ & \\
\hline Black African & $4.0(3.3$ to 5.0$)$ & & $2.6(1.9$ to 3.8$)$ & & $2.9(2.3$ to 3.5$)$ & \\
\hline Black other & $12.4(9.8$ to 15.6$)$ & & $12.0(8.9$ to 16.3$)$ & & $5.2(4.1$ to 6.6$)$ & \\
\hline Asian/other & $1.0(0.7$ to 1.4$)$ & & $2.2(1.5$ to 3.2$)$ & & $2.4(1.9$ to 3.0$)$ & \\
\hline Age group & & $<0.0001$ & & $<0.0001$ & & $<0.0001$ \\
\hline $15-19$ years & $1.6(1.3$ to 2.0$)$ & & $14.2(10.8$ to 18.6$)$ & & $11.0(9.3$ to 13.2$)$ & \\
\hline $20-24$ years & $2.3(1.9$ to 2.7$)$ & & $8.6(6.7$ to 11.2$)$ & & $6.6(5.6$ to 7.8$)$ & \\
\hline $25-29$ years & $2.1(1.8$ to 2.5$)$ & & $3.3(2.5$ to 4.4$)$ & & $2.9(2.4$ to 3.5$)$ & \\
\hline $30-59$ years & 1 (reference) & & 1 (reference) & & 1 (reference) & \\
\hline $\begin{array}{l}\text { Townsend score } \\
\text { (quartile) }\end{array}$ & & $<0.0001$ & & $<0.0001$ & & $<0.0001$ \\
\hline 1 (least deprived) & 1 (reference) & & 1 (reference) & & 1 (reference) & \\
\hline 2 & $1.6(1.3$ to 2.0$)$ & & $1.5(1.1$ to 2.1$)$ & & $1.4(1.2$ to 1.6$)$ & \\
\hline 3 & $2.3(1.9$ to 2.9$)$ & & $2.0(1.5$ to 2.6$)$ & & $1.5(1.3$ to 1.8$)$ & \\
\hline 4 (most deprived) & $2.2(1.8$ to 2.7$)$ & & 2.1 (1.6 to 2.8$)$ & & $1.4(1.2$ to 1.6$)$ & \\
\hline
\end{tabular}

* Random effects Poisson regression models, controlling for all variables in the table.

tp Values derived from likelihood ratio tests. 
mitters, reflecting the local burden of infection better than previously presented person based rates. ${ }^{5}$ Our analyses, however, underestimate overall rates of gonorrhoea and chlamydia. Firstly, our data from 1994-5 do not capture nationwide increases in infections diagnosed in genitourinary clinics up to $1998 .{ }^{16}$ Surveillance systems collecting disaggregate data should provide more timely analyses. ${ }^{17}$ Secondly, studies of this kind exclude infections diagnosed outside genitourinary clinics. This affects rates of chlamydia more than gonorrhoea because more chlamydia testing is carried out in other healthcare settings. In 1997-8, only $58 \%$ (18 738/32 241) of specimens tested in one of two laboratories in Lambeth, Southwark and Lewisham were sent from genitourinary clinics. $^{18}$

Relative differences between ethnic groups may also be biased. Firstly, rates in the black other group are overestimated because this group included $3.6 \%(722 / 3372)$ of episodes in black people that could not be assigned to a more specific category. In sensitivity analyses that excluded reassigned episodes rates in the black other group remained between those of black Caribbeans and Africans (data not shown). Secondly, gonorrhoea rates in white men are overestimated by including episodes acquired through sex between men, the majority of whom are white. Thirdly, differential sexual health service use by ethnic groups may account for some of the observed disparity but the extent of this cannot be estimated because data are currently unavailable. Fourthly, poor socioeconomic conditions may confound associations between ethnic group and disease. ${ }^{119}{ }^{20}$ Controlling for a ward level deprivation score slightly attenuated the association between black ethnicity and infection but, although ecological measures are imprecise, residual confounding is unlikely to account for the large differences and our findings are consistent with studies in the United States. ${ }^{21}$

ETHNIC INEQUALITIES IN RATES OF SEXUALLY TRANSMITTED INFECTIONS

Scientific research into race or ethnicity and health has often been racist, proposing innate inequalities that predispose to stigmatised diseases $^{22}{ }^{23}$ and the field of sexually transmitted infections is particularly vulnerable to accusations of racism. The reason for collecting ethnic group data in epidemiological studies should therefore always be justified and the choice of categories should be consistent with a priori hypotheses. ${ }^{24}$ This study was conducted to demonstrate that there are differences in rates of gonorrhoea and chlamydia between census defined black ethnic groups that have previously been overlooked ${ }^{2-6}$ because ethnic groups have been lumped together. ${ }^{22}$ Although we reported rates in a combined group of Asians and others, because of small numbers we have not made any inferences from this heterogeneous group. The 1991 UK census has been criticised because the ethnic categories arbitrarily conflate racial, geographical, and national characteristics ${ }^{22}$ but this is the only source of national data that allows population based rates to be calculated and compared with other studies.

DIFFERENT EPIDEMICS OF SEXUALLY

TRANSMITTED INFECTIONS IN DIFFERENT ETHNIC GROUPS

In the United Kingdom differences in rates of AIDS between black ethnic groups have previously been documented, with an estimated incidence of 98 per 100000 in black Africans compared with 9 per 100000 in black Caribbeans in the United Kingdom in 1994$5^{25}$ and concern about the increasing risk of HIV infection in black Caribbeans, fuelled by high rates of bacterial sexually transmitted infections, has been voiced. ${ }^{25}{ }^{26}$ In the United States rates of both bacterial sexually transmitted infections and HIV/AIDS are higher in African-Americans than white people, ${ }^{1}$ leading to common social and behavioural hypotheses explaining differences in the risk of both infections. In one study of inner city women, however, sexually transmitted infections including HIV were found to be more common among US born than foreign born women, the majority of whom were from Caribbean countries. ${ }^{27}$ In the United Kingdom, the paradoxes of higher rates of HIV/AIDS in black Africans and of gonorrhoea and chlamydia in black Caribbeans, and of high rates of HIV/AIDS but lower rates of bacterial infections in black Africans require explanation. Assortative sexual mixing according to country of birth of attenders at one clinic in Lambeth, Southwark and Lewisham has previously been described and assortativeness increased when origin was reassigned taking into account parental country of birth. ${ }^{28}$ This study supports the hypothesis that sexual mixing patterns may explain the limitation of HIV infection to the sub-Saharan African population ${ }^{28}$ and of gonorrhoea and chlamydia to those of black Caribbean origin. Sexual networks within ethnic groups should also be considered. Laumann and Youm have described a regression model in which higher sexually transmitted infection rates in AfricanAmericans are explained by greater mixing between core group (with more than four partners in the past year) and non-core members than in the white population. ${ }^{29}$

\section{FURTHER RESEARCH}

There is continuing debate on the nature of ethnicity with approaches ranging from those that single out an objective trait such as language or religion to those emphasising subjective feelings of kinship based on shared characteristics. ${ }^{30}$ In health sciences an accepted definition of ethnicity groups people according to specific shared characteristics including geographical and ancestral origins, cultural traditions, and languages but recognises that these are subjective and fluid. ${ }^{22}$ The census categories black African, black Caribbean, black other are inadequate measures of the social, cultural, and behavioural factors that might explain between group differences but demonstrating inequalities is a necessary precursor to generating hypotheses for further study. We are currently undertaking qualitative 
and quantitative aetiological studies that include a detailed description of ethnicity, country of birth, and parental country of birth and examine a variety of exposures including sexual behaviour, sexual mixing patterns, experience of discrimination, social, economic, and educational status to explore reasons for these observed inequalities. ${ }^{31}$ Different approaches to prevention for different infections and for different ethnic groups are required and further research in this area is also needed.

In summary, we have described differences in rates of gonorrhoea and chlamydia between black ethnic groups, with higher rates in black Caribbeans than black Africans. Of particular concern, among teenage women from black Caribbean backgrounds, $2.6 \%$ per year are diagnosed with gonorrhoea and $4.6 \%$ with chlamydia. Our study suggests that differences in disease occurrence between black ethnic groups should be explored before combining data, even when numbers of episodes are small. Confidence intervals should then be used to describe imprecision in estimates for each group. Studies seeking to explain ethnic differences should use a range of descriptive variables to measure ethnicity that will help distinguish between the contribution of cultural, economic, and behavioural factors. ${ }^{24}$

Contributors: NL designed the study, did the fieldwork and drafted the manuscript; NL and JS did the statistical analysis; JS commented on the manuscript; DB contributed data from Guy's and St Thomas' Trust, contributed to interpreting the results, and commented on the manuscript.

Fieldwork for this study was undertaken by Dr Low at the Caldecot Centre, King's NHS Healthcare Trust, London. We Caldecot Centre, King's NHS Healthcare Trust, Lond

would like to thank Dr Anton Pozniak for his support.
Mr B Cappi, Mr R Halai, Mr M Moreno, Ms C Shergold, and Mr B Cappi, Mr R Halai, Mr M Moreno, Ms C Shergold, and
Ms A Smith helped in the retrieval of data. The following conMs A Smith helped in the retrieval of data. The following consultants in genitourinary medicine allowed us to use information
from their clinics: Dr S Barton, Dr F Davidson, Dr BA Evans, from their clinics: Dr S Barton, Dr F Davidson, Dr BA Evans, Dr P French, Dr PE Hay, Dr R Lau, Dr A Law
Lister, Dr D Mercey, Dr S Mitchell, Dr J Russell.

Lister, Dr D Mercey, Dr S Mitchell, Dr J Russell.
Funding: Dr Nicola Low was funded by a South Thames NHS Executive Health Services research training fellowship.

Conflict of interest: none.

1 US Department of Health and Human Services, Public Health Service. Division of STD Prevention. Sexually transmitted disease surveillance, 1997. Atlanta, GA: Center for Disease Control and Prevention (CDC), 1998

2 Hickman M, Judd A, Maguire H, et al. Incidence of gonorrhoea diagnosed in GUM clinics in South Thames (West) Region. Sex Transm Inf 1999;75:306-11.

3 Shahmanesh M, Gayed S, Ashcroft M, et al. Geomapping of chlamydia and gonorrhoea in Birmingham. Sex Transm Inf 2000;76:268-72

4 Lacey CJN, Merrick DW, Bensley DC, et al. Analysis of the sociodemography of gonorrhoea in Leeds, 1989-93. BMF 1997;314:1715-18.

5 Low N, Daker-White G, Barlow D, et al. Gonorrhoea in inner London: results of a cross sectional study. BMF 1997 314:1719-23.
6 Winter AJ, Sriskandabalan P, Wade AA, et al. Sociodemography of genital Chlamydia trachomatis in Coventry, UK, raphy of genital Chlamydia trachomatis

7 Hahn RA, Magder LS, Aral SO, et al. Race and the prevalence of syphilis seroreactivity in the United States population: a national sero-epidemiologic study. $A m$ f Public Health 1989;79:467-70.

8 Rice RJ, Roberts PL, Handsfield HH, et al. Sociodemographic distribution of gonorrhea incidence: implications for prevention and behavioral research. Am f Public Health 1991;81:1252-8.

9 Zimmerman HL, Potterat JJ, Dukes RL, et al. Epidemiologic differences between chlamydia and gonorrhea. Am 7 Public Health 1990;80:1338-42.

10 Fenton S. Ethnicity: racism, class and culture. London: MacMillan Press, 1999.

1 McKenzie KJ, Crowcroft NS. Race, ethnicity, culture, and science[editorial] BMF 1994;309:286-7.

12 Annual Report of the Director of Public Health. Past, present and future: 1997-1998. London: Lambeth, Southwark and Lewisham Health Authority, 1998.

13 Teague A. Ethnic group;first results from the 1991 census. Popul Trends 1993;72:12-17.

14 Storkey M, Maguire J, Lewis R. Cosmopolitan London-past, present and future. London: London Research Centre, 1997.

15 Office of Population Censuses and Surveys and General Register Office Scotland. Undercoverage in Great Britain, 58. London: Office of Population Censuses and Surveys, 1994.

16 Lamagni TL, Hughes G, Rogers PA, et al. New cases seen at genitourinary medicine clinics: England 1998. Commun Dis Rep 1999;9(Suppl 6):S1-12.

17 Catchpole MA, Harris JR, Renton A, et al. Surveillance of sexually transmitted infections: fit for purpose? [editorial] Int F STD AIDS 1999;10:493-4.

18 Low N. Implementing chlamydia control activities in nongenitourinary settings in Lambeth, Southwark and Lewisham. London: Lambeth, Southwark and Lewisham Health Authority, 1998.

19 Ethnicity, race, and culture: guidelines for research, audit, and publication. BMF 1996;312:1094-5.

20 Ross MW. Race and ethnicity in STD analyses [editorial] Sex Transm Inf 1998;74:2-3.

21 Ellen JM, Kohn RP, Bolan GA, et al. Socioeconomic differences in sexually transmitted disease rates among black and white adolescents, San Francisco, 1990 to 1992. Am f Public Health 1995;85:1546-8.

22 Bhopal R. Is research into ethnicity and health racist, unsound, or important science? BMF 1997;314:1751-6.

23 Osborne NG, Feit MD. The use of race in medical research. 7AMA 1992;267:275-9.

24 McKenzie K, Crowcroft NS. Describing race, ethnicity, and culture in medical research [editorial] BMF 1996;312: 1054

25 De Cock KM, Low N. HIV and AIDS, other sexually transmitted diseases and tuberculosis in ethnic minorities in the United Kingdom: is surveillance serving its purpose? $B M F$ 1997;314:1747-51.

26 Daker-White G, Barlow D. Heterosexual gonorrhoea at St Thomas'-I: patient characteristics and implications for targeted STD and HIV prevention strategies. Int f STD AIDS 1997;8:32-5.

27 DeHovitz JA, Kelly P, Feldman J, et al. Sexually transmitted diseases, sexual behavior, and cocaine use in inner-city women. Am ₹ Epidemiol 1994;140:1125-34.

28 Barlow D, Daker-White G, Band B. Assortative sexual mixing in a heterosexual clinic population-a limiting factor in HIV spread? AIDS 1997;11:1041-6.

29 Laumann EO, Youm Y. Racial/ethnic group differences in the prevalence of sexually transmitted diseases in the United States: a network explanation. Sex Transm Dis 1999;26:250-61.

30 Hutchinson J, Smith AD, eds Concepts of ethnicity. Section 1. In: Ethnicity. Oxford: Oxford University Press, 1996:15-

31 Connell P, McKevitt C, Low N. Sexually transmitted infections among black young people in south east London: results of a rapid ethnographic assessment. Culture, Health and Sexuality 2000 (in press). 